\title{
Role of tapioca peel activated carbon (TPAC) in decolourisation of Red Brown C4R reactive dye
}

\author{
C. Parvathi ${ }^{1}$, T. Maruthavanan ${ }^{2}$, S. Sivamani ${ }^{3}$, C. Prakash ${ }^{4}$ and C.V.Koushik ${ }^{4}$ \\ ${ }^{1}$ Dept. of Chemistry, VSA School of Engineering, VSA Group of Institutions, Uthamasolapuram, Salem-636 010,India. \\ ${ }^{2}$ Dept. of Chemistry, Sona starch, Sona College of Technology, Salem 636 005, India \\ ${ }^{3}$ Dept. of Biotechnology, VMKV Engineering College, Salem 636 005, India \\ ${ }^{4}$ Dept. of Fashion Technology, Sona College of Technology, Salem 636 005, India \\ dearparvathi@rediffmail.com
}

\begin{abstract}
A carbon sorbent derived from an agricultural waste, tapioca peel was applied to study the removal of a reactive dye, Red Brown C4R from aqueous solution. Batch experiments were performed as a function of process parameters like agitation time, initial dye concentration and carbon dose. Modified Ritchie second order equation better predicted the kinetic results compared to other rate equations (pseudo first order \& pseudo second order) tested. Among the isotherm models applied to the equilibrium data Freundlich model better predicted the experimental values. The adsorption capacity was $121.47 \mathrm{mg} \mathrm{g}^{-1}$ at an initial $\mathrm{pH}$ of 6 and at $32 \pm 0.5^{\circ} \mathrm{C}$. The adsorption capacity increased with increase in temperature. The influence of $\mathrm{pH}$ on dye removal was not significant. An optimum carbon dose of $1.2 \mathrm{~g} \mathrm{~L}^{-1}$ was required for the maximum removal (96\%) of dye from its $60 \mathrm{mg} \mathrm{L}^{-1}$ solution.
\end{abstract}

Keywords: Adsorption, Red Brown C4R, tapioca peel, activated carbon, kinetics, isotherms

Introduction

Activated carbon has widely been used for the removal of inorganic and organic pollutants from aqueous solution. In a continuing search for the adsorbents, various lignocellulosic materials or agriculture wastes such as coconut shell, rice husks, saw dust, and wheat straw were used (Srivastava et al., 1987; Usmani ,1988; Rahman, 2000). These materials were pyrolysed or carbonized in an inert atmosphere in order to remove volatile organic constituents, leaving behind a highly porous carbonaceous residue, followed by either chemicals, steam or gas activation for removal of the pollutants. Red Brown C4R has long been used as a model for the adsorption of organic pollutants from aqueous solution. A number of studies on the removal of Red Brown C4R from aqueous solution by using corncobs (El-Hendawy et al., 2001), palm-tree cobs (Avon, 1997) oil palm nut shells (Chan, 1980) olive-waste (Bcaoui et al., 2001) oil shale rock (Abu-El-Shar et al., 2000) and chitin (Annadurai et al., 1999) were reported.

Activated carbons have been prepared from the above materials by application of both physical and chemical activations. Activation and pyrolysis of rice husks with $\mathrm{ZnCl}_{2}, \mathrm{H}_{3} \mathrm{PO}_{4}$ or $\mathrm{CO}_{2}$ have been used for the adsorption of Red Brown C4R (Tanin \& Gurgey, 1987) and benzene (Tanin \& Gurgey, 1988). Separate and sequential application of physical activation with steam and chemical activation with $\mathrm{H}_{3} \mathrm{PO}_{4}$ were also reported (Lafi, 2000; El-Hendawy et al., 2001). Hu and Srinivasan (2001) employed simultaneous activation by using $\mathrm{ZnCl}_{2}$ and $\mathrm{CO}_{2}$ to produce activated carbon from coconut shells and palm seeds.

Tapioca peels are agricultural by-product that is currently of no economic value. They consist of tiny bean- like particles and are disseminated throughout the tapioca pulp, and are considered as waste product during sago production. It was reported (Bourgeois et al., 2001) that the peels consist of high amount of lignocellulosic materials. Thus, it should be possible to carbonize or pyrolyse the material to form a porous carbon that is suitable to be used as adsorbent. In this work, we used tapioca peels as a raw material to produce activated carbons. We used physical activation (carbonization or pyrolysis) in an inert gas, followed by sequential chemical (Sulphuric acid) and physical activations to produce activated carbon. The use of such materials for the production of activated carbon has not been reported before.

\section{Materials and methods}

Tapioca peels were collected from nearby industries and then cleaned. It was dried in sunlight for $6 \mathrm{hr}$ and then powdered in a domestic Sumeet mixie. It was washed with water to remove unwanted materials present in it and then filtered. Again, it was dried for $4 \mathrm{~h}$ and then activated with concentrated sulfuric acid before carbonization. Then, the material was carbonized at $200^{\circ} \mathrm{C}$ in a hot air oven under controlled conditions. Then to get rid of excess sulfuric acid, the carbon was repeatedly washed and finally dried. The carbonized material was sieved to 100 microns using Lawrence and Mayo sieve shaker and used for adsorption.

\section{Adsorption studies}

Various concentrations of Red Brown C4R solutions ranging from $10-100 \mathrm{mg} \mathrm{dm}^{-3}$ were prepared by dissolving Red Brown C4R crystals in distilled water. A calibration curve of absorbance versus concentration was constructed, using a UV Spectrophotometer (Hitachi model, U-2000) at maximum wavelength of $670 \mathrm{~nm}$.
Research article

CIndian Society for Education and Environment (iSee)
"Activated carbon from Tapioca peels" http://www.indjst.org
Parvathi et al. Indian J.Sci.Technol. 
Vol. 3 No. 3 (Mar 2010)

ISSN: 0974- 6846
Adsorption isotherm of Red Brown C4R were obtained by adding $0.1 \mathrm{~g}$ of TPAC sample to a $0.250 \mathrm{dm}^{3}$ flask containing $0.100 \mathrm{dm}^{3}$ of $10 \mathrm{mg} \mathrm{dm}^{-3}$ aqueous solution of Red Brown C4R. The flask was kept in a thermostat shaker at $30^{\circ} \mathrm{C}$ for $45 \mathrm{~min}$. The suspension was then filtered, and the concentration of the Red Brown C4R was determined by difference. The procedure was extended to determine optimum shaking time, concentration and the amount of adsorbent used.

\section{Results and discussions}

\section{Effect of mixing time}

The adsorption behaviours of the samples were studied by evaluating the removal efficiency, $R_{E}$, of Red Brown C4R, calculated as:

$R_{E}=\left(C_{0}-C\right) / C_{0} \times 100$

Where, $C_{0}$ is the initial concentration of aqueous solution of Red Brown C4R replaced in a flask and shaken at room temperature for a certain time with a weighed sample, and $C$ is the solution concentration after adsorption, $R_{E}$ is expressed in term of percentage. The removal percentage increases with an increase in time (Fig.1).

The adsorption mechanism of the above data can be expressed in-terms of logarithmic plot of $R_{E}$ versus mixing time in hour as:

$\log \mathrm{R}_{\mathrm{E}}=m \log \mathrm{t}+\log \mathrm{K}(2)$

Where, $m$ is the slope and may represent adsorption mechanism while $\mathrm{K}$ is a constant may represent rate factor (Bourgeois et al., 2001). Regression analysis of the data reveals that increase in the surface area of the samples results in a decrease in slope values with corresponding increase in the factor $\mathrm{K}$. Smaller values of $m$ for larger surface areas indicate better adsorption, whereas higher values of rate factor, $\mathrm{K}$, indicate a faster rate of Red Brown C4R removal (Table 1). Additional experiment showed that a relatively
Table 1. Parameters for the log $R_{E} V s$

$\log \mathrm{t}\left(\mathrm{C}=10 \mathrm{mg} \mathrm{dm} \mathrm{m}^{-3}\right.$, volume $\left.0.100 \mathrm{dm}^{3}\right)$
\begin{tabular}{|c|c|c|c|}
\hline $\begin{array}{c}\text { Surface } \\
\text { area }\left(\mathrm{m}^{2} \mathrm{~g}^{-1}\right)\end{array}$ & Slope $\mathrm{m}$ & $\log \mathrm{K}$ & $\mathrm{r}^{2}$ \\
\hline 13 & 0.89 & 1.25 & 0.94 \\
\hline 178 & 0.49 & 1.64 & 0.99 \\
\hline 308 & 0.49 & 1.67 & 0.99 \\
\hline 314 & 0.09 & 1.74 & 0.96 \\
\hline
\end{tabular}

Fig. 1. Removal efficiency of Red Brown C4R versus time.

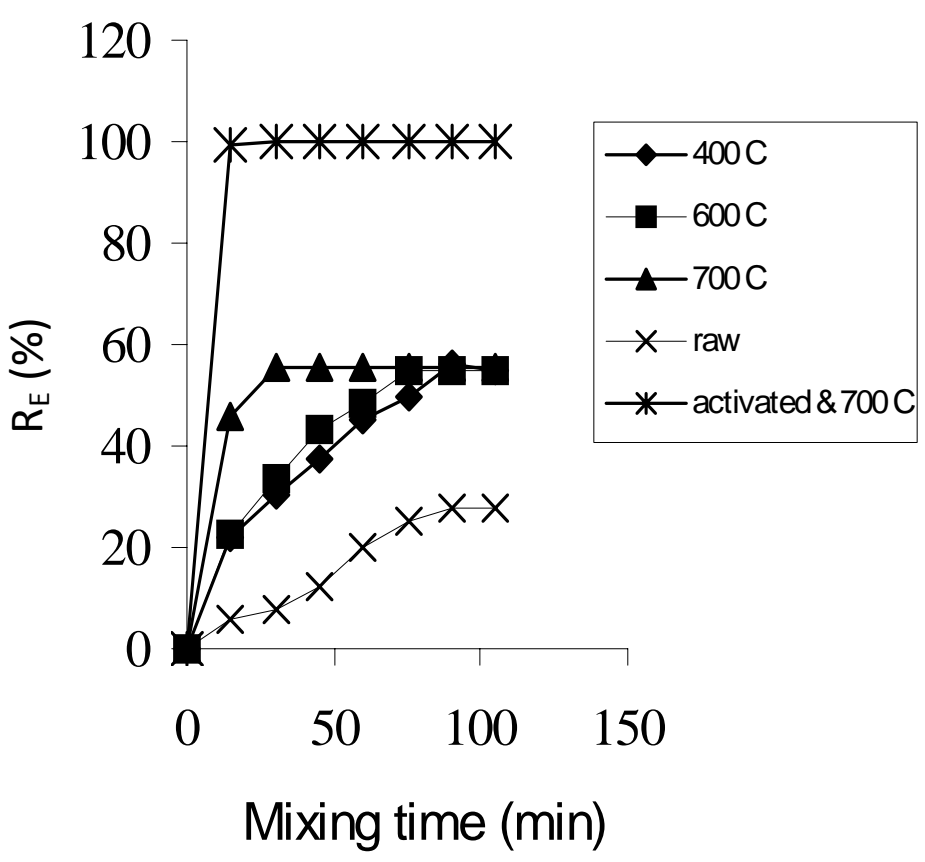

observed, resulting in complete removal of Red Brown C4R. The effectiveness of sulphuric acid as activation agent was widely noted in the literature (Chan, 1980; Usmani, 1988; Hu \& Srinivasan, 2001).

The adsorption isotherms of Red Brown C4R onto the activated guava seeds were carried out by applying the linear Langmuir equation

$$
\frac{\mathrm{C}_{e}}{\mathrm{X}_{\mathrm{e}}}=\frac{1}{\mathrm{X}_{\mathrm{m}} \mathrm{K}}+\frac{1}{\mathrm{X}_{\mathrm{m}}} \mathrm{C}_{\mathrm{e}}
$$

and the Freundlich equation $\log X_{e}=\log K_{F}+1 / n \log C_{e}$

Where, $C_{e}$ is the amount of adsorbate in the solution at small quantity of activated sample with surface area of $600 \mathrm{~m}^{2} \mathrm{~g}^{-1}$, required only $0.3 \mathrm{~g}$ to remove all Red Brown C4R (10 $\mathrm{mg} \mathrm{dm}^{-3}$ ), as compared to $2 \mathrm{~g}$ required for the raw sample. Smaller values of $\mathrm{K}$ for comparatively smaller surface area may be due to the comparatively smaller pore volume or active sites on the tapioca peels.

On pyrolysis of tapioca peels up to $700^{\circ} \mathrm{C}$, organic constituents were decomposed, leaving behind porous materials containing exposed active sites. However, the surface areas at these temperatures were relatively low and the materials were able to remove Red Brown C4R up to $\sim 55 \%$. Since only pores larger than the size of adsorbate molecule were accessible to the adsorbate, it is believed that the some pores in the pyrolysed samples were blocked by decomposition products of the organic constituents, thus inhibiting the accessibility of the active sites for the adsorption. After activation of the sample with sulphuric acid, a double increase in surface area was equilibrium, $X_{e}$ is the amount of adsorbate adsorbed, $X_{m}$ is the amount of adsorbated adsorbed to form monolayer coverage, and $\mathrm{K}_{\mathrm{L}}, \mathrm{n}$ and $\mathrm{K}_{\mathrm{F}}$ are the equation constants.

When the adsorption data was tested using equations (3) and (4), they best fitted to the Freundlich model as indicated by its relatively higher linear correlation coefficients (Table 2). Fig. 2a \& b represent comparison of the experimental data of activated carbons with Langmuir and Freundlich equations. The results show that activated carbon prepared from tapioca peels exhibit good capacity to remove the bulky dye molecule through chemical activation followed by pyrolysis at $700^{\circ} \mathrm{C}$.

\section{Conclusions}

We demonstarated the production of activated carbon derived from tapioca peels. Carbonization in inert gas produced poorly activated carbons due to the incomplete decomposition of organic constituents as carbonization by-products blocked the pores. However, activation by 
Indian Journal of Science and Technology

Fig. 2. Fitting adsorption data with

(a) Langmuir model and (b) Freundlich model
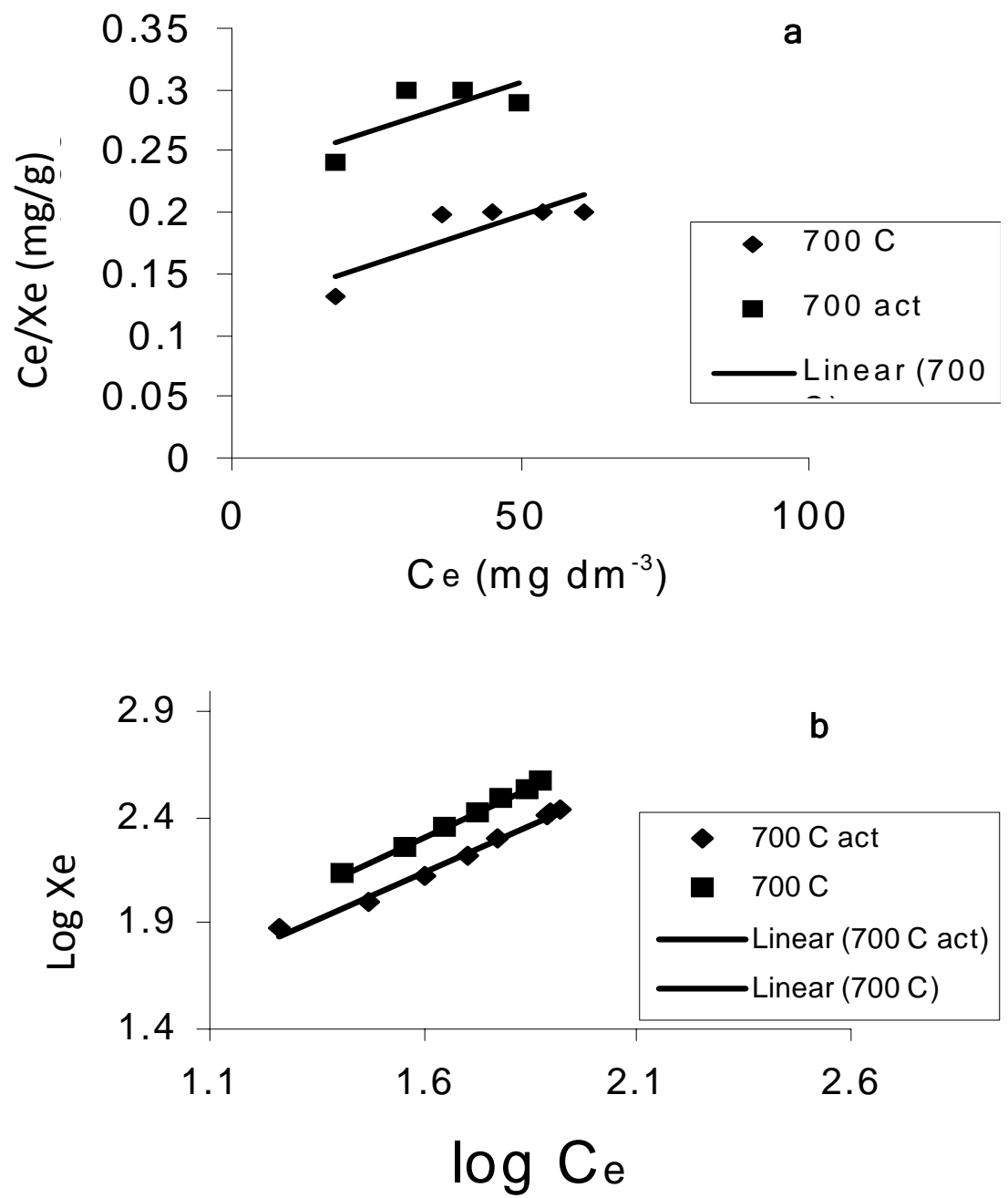

Vol. 3 No. 3 (Mar 2010)

ISSN: 0974- 6846

mill wastes (JEFT) and solid residues from refined Jordanian oil shale. Environ. Geology. 39, 1090-1094.

2. Annadurai G, Sheeja RY, Mathalai S, Murugesan $T$ and Srinivasamoorthy VR (1999) Factorial design of experiments in the determination of adsorption equilibrium constants for basic methylene blue using biopolymer. Bioproc. Engg. 20, 37-43.

3. Avon J, Ketcha Mbadcam J, Noubactep C and Germain P (1997) BET surface areas and pore volume distributions of the activated carbon, Carbon. 35(3), 365-369.

4. Bcaoui A, Yaacoubi A, Dahbi A, Bennouna C, Phan Tan Luu R, Maldonado-Hodar FJ, Rivera-Utrilla $\mathrm{J}$ and Moreno-Castilla $\mathrm{C}$ (2001) Activated carbon from olive-waste cakes. Carbon. 39, 425-432.

5. Bourgeois $P$, Guylene $S$, Jacqueline $A$ and Joseph H (1988), Adsorption studies on reactive dyes, Agricultures. 7(2), 105.

6. Chan KC, Goh SH, Toh TH, Tan $\mathrm{WI}$ and Tang TS (1980) Activated carbon from palm (Elaeis guineensis) nut shells. Malaysian J. Sci. 6, 131- 137.

7. El-Hendawy AA, Samra SE and Girgis BS (2001) Adsorption characteristics of activated carbons obtained from corncobs. Colloids and surface A: Physicochemical and engineering aspects. 180(3), 209-221.

8. $\mathrm{Hu} Z$ and Srinivasan MP (2001) Mesoporous high surface area activated carbon. Microporous Mesoporous Mat. 34, 267-275.

9. Lafi WK (2000) Production of activated carbon from acorns and olive seeds.
Table 2. Parameters for the adsorption of Red Brown C4R

\begin{tabular}{|c|c|c|c|}
\hline \multicolumn{3}{|c|}{ Samples } \\
\hline Model & Parameter & $700^{\circ} \mathrm{C}$ & $700^{\circ} \mathrm{C}$ activated \\
\hline \multirow{5}{*}{ Langmuir } & $\mathrm{r}^{2}$ & 0.508 & 0.713 \\
& $\mathrm{~K}_{\mathrm{L}}$ & 6.504 & 13.400 \\
& $\mathrm{X}_{\mathrm{m}}$ & 0.667 & 0.625 \\
& $\mathrm{r}^{2}$ & 0.988 & 0.999 \\
& $\mathrm{~K}_{\mathrm{F}}$ & 5.261 & 6.174 \\
& $\mathrm{n}$ & 1.052 & 1.122 \\
\hline
\end{tabular}

sulphuric acid followed by pyrolysis at $700^{\circ} \mathrm{C}$ proved very effective in producing better quality activated carbon with well-developed porosity and optimum adsorption capacity.

\section{References}

1. Abu-El-Sha'r WY, Gharaibeh $\mathrm{SH}$ and Mahmoud $\mathrm{S}$ (2000) Removal of dyes from aqueous solutions using low-cost sorbents made of solid residues from olive-
Biomass Bioenergy. 20, 57-62.

10.Rahman IA, Ismail J and Osman H (2000) Studies on $\mathrm{Zn}$ (II) ion adsorption by rice husks digested with nitric acid. Malaysian J. Chem. 2(1), 12-15

11.Srivastava SK, Pant N and Pal N (1987) Studies on the efficiency of a local fertilizer waste as a low cost adsorbent. Water Res. 21(11), 1389-1394.

12. Tanin S and Gurgey I (1987) Adsorption of reactive dyes by modified activated carbon, Chimica Acta Turcica. 15, 461-475.

13.Tanin S and Gurgey I (1988), Adsorption of disperse dyes by modified activated carbon, Chimica Acta Turcica. 16, 57-63.

14. Usmani TH, Wahab T and Ahmand SZ (1988) Effect of chemical treatment on the properties of activated carbon from indigenous agro wastes. Pakistan J. Sci. Res. 31(3), 221-224.
Research article

CIndian Society for Education and Environment (iSee)
"Activated carbon from Tapioca peels" http://www.indjst.org
Parvathi et al. Indian J.Sci.Technol. 